\title{
Male Infertility: Evaluation and Treatment
}

Hamad Mohamed ZB', Hamad Alfarisi $H A^{a}$, Abdul Wahab AY $Y^{b}$, Abd Fuaat $A^{c}$, Che Mohamad $C A^{d}$, Ibrahim $M^{a}$ aDepartment of Nutrition Sciences, Kulliyyah of Allied Health Sciences, International Islamic University Malaysia

${ }^{b}$ Department of Obstetrics and Gynaecology, Kulliyyah of Medicine, International Islamic University Malaysia 'Department of Pathology \& Laboratory Medicine, International Islamic University Malaysia Medical Centre ${ }^{\mathrm{d} D e p a r t m e n t}$ of Basic Medical Sciences, Kulliyyah of Pharmacy, International Islamic University Malaysia

\section{ABSTRACT}

Globally, 48.5 million couples are suffering from infertility. One of six couples in United Kingdom is categorized as infertile. In developing countries, infertility affects one of four couples. Male infertility constitutes about $40-50 \%$ of the incidence. A minimum of 30 million men worldwide are infertile. Mortality rate is higher in men with impaired semen quality than those who have normal semen quality. The initial evaluation of a male partner of an infertile couple should be done if there is a delay in the pregnancy in the female partner for one year or more from unprotected sexual intercourse. It can be done earlier if there is a predisposing factor for infertility. Identification of the underlying aetiology of infertility is the guide for treatment course which could be medical, surgical or through assisted reproductive technology. The aim of this review is to highligh the main courses of evaluation and treatment of male infertility.

KEYWORDS: Male infertility; Evaluation; Treatment

\section{INTRODUCTION}

Infertility is defined as a failure to conceive in sexually active noncontracepting couples for a period of one year or more. ${ }^{1}$ Globally 48.5 million couples are suffering from infertility. ${ }^{2}$ The prevalence of infertility differs between different countries. It is higher in underdeveloped than in developed countries due to poor diagnostic and therapeutic options in underdeveloped countries. One of six couples in United Kingdom is categorized as infertile whereas in developing countries, infertility affecting one of four couples. ${ }^{3,4}$ The failure of a male to induce pregnancy in a fertile female is referred as male infertility which constitutes about $40-50 \%$ of the incidence. ${ }^{5} \mathrm{~A}$ minimum of 30 million men worldwide are infertile. The percentage of infertile men in North America is $4.5 \%-6 \%$, in Australia is $8 \%-9 \%$ and in central Eastern Europe is $8 \%-12 \%$. No enough data available pertaining the percentage of infertile men in Latin America and Asia due to underreporting there. ${ }^{6}$ Analysis of data on semen quality from papers

Corresponding Author:

Assoc. Prof. Dr. Muhammad Bin Ibrahim

Department of Nutrition Sciences,

Kulliyyah of Allied Health Sciences,

International Islamic University Malaysia, 25200

Kuantan, Pahang, Malaysia

Tel No : +60139234998

Email : abumaisarah@iium.edu.my published worldwide between 1938 and 1990 have revealed that semen quality and fecundity have been declining over the previous five decades. ${ }^{7}$ It was also reported that the mortality rate is higher in men with impaired semen quality than those who have normal semen quality. Moreover, the risk of death is increasing with the increase in the number of abnormal sperm parameters. ${ }^{8}$ Inability to conceive and get a child can be devastating to the affected couples in different aspects of their life, as it is associated with psychological distress, impairs relationship abilities, marital life and family life, on top of their sexual or reproductive aspects. ${ }^{9}$

\section{Evaluation of Male Infertility}

The initial evaluation of a male partner of an infertile couple should be conducted if there is a delay in the pregnancy in the female partner for one year or more from unprotected sexual intercourse. It can be done earlier if there is a predisposing factor for infertility such as a previous history of cryptorchidism, or if there is a known risk factor for infertility in the female partner such as an age older than 35 years. ${ }^{10}$ It should include a complete reproductive history and analysis of at least two properly performed semen samples. If any abnormality is detected, a thorough medical history 
and physical examination should be included in the evaluation. $^{11}$

\section{Semen Analysis}

Semen analysis is one cornerstone in the evaluation of infertile couples however, normal semen analysis does not guarantee normal fertility. ${ }^{12}$ Semen analysis can show a reduction in sperm count (oligozoospermia), reduction in motility (asthenozoospermia), abnormal sperm morphology (teratozoospermia) or a combination of these abnormalities (oligo-astheno-teratozoospermia). ${ }^{13}$ According to WHO guidelines 2010, the lower reference limit for semen volume is $\mathbf{1 . 5}$ millilitre, for total motility is $40 \%$, for vitality (membrane-intact spermatozoa) is $58 \%$, for sperm concentration is $15 \times$ $10^{6}$ spermatozoa per millilitre, for total sperm number is $39 \times 10^{6}$ spermatozoa per ejaculate and for normal forms is $4 \% .{ }^{14}$ More specialized tests may be required in some cases and these tests include quantification of leukocytes in semen, sperm viability test, tests for anti-sperm antibodies, sperm deoxyribonucleic acid (DNA) fragmentation tests and reactive oxygen species. ${ }^{12}$ These tests should be reserved for infertile men with unexplained infertility or in whom the identification of cause will direct treatment such as assisted reproductive technology. ${ }^{10}$

\section{Endocrine Evaluation}

Endocrine disorders are very rare in men with normal semen analysis. Endocrine evaluation is indicated in men who have abnormal sperm parameters, impaired sexual function, or have clinical manifestations of endocrine disorders. ${ }^{12}$ If sperm concentration is low, serum total testosterone and serum follicle stimulating hormone (FSH) should be taken to differentiate between primary and secondary hypogonadism. Low testosterone with low FSH indicates secondary hypogonadism whereas, low testosterone with high FSH indicates primary hypogonadism. ${ }^{15}$ A normal FSH cannot rule out spermatogenesis impairment; however, elevation of FSH even in the upper limit of normal is an indicator of spermatogenesis impairment. ${ }^{11}$ If serum total testosterone is low, serum luteinizing hormone (LH) and prolactin levels should be measured to assess for pituitary causes. ${ }^{16}$ In azoospermia, it is necessary to determine if it is due to obstructive or non-obstructive causes, normal bilateral testicular volume with normal FSH level is a reasonable predictor for obstructive pathology. ${ }^{13}$ Serum inhibin $B$ was suggested to be a better indicator for the fertility status of men than FSH. However, due to the high cost of inhibin B measurement, FSH remains the preferred test for male infertility screening. ${ }^{12}$ Measurement of serum estradiol level and determination of serum testosterone to estradiol ratio should be measured as they can affect male fertility. ${ }^{17}$ Thyroid function test should be included in the endocrine evaluation of infertile men as both hypothyroidism and hyperthyroidism have a deleterious effect on sperm parameters. ${ }^{18}$

\section{Other Diagnostic Tools for Male infertility}

Post-ejaculatory urine analysis is indicated for men having ejaculate volume less than 1 millilitre who have not diagnosed previously as cases of bilateral vassal agenesis or having clinical manifestations of hypogonadism. ${ }^{10}$ For men who suspected to have an ejaculatory duct obstruction trans-rectal ultrasonography is indicated whereas, scrotal ultrasonography is indicated if scrotal examination is difficult or inadequate, and if testicular mass is suspected. ${ }^{11}$ To discriminate between testicular failure and obstruction in azoospermic men, testicular biopsy is recommended. ${ }^{16}$ Microbiologic assessment is indicated if there is urinary tract infection and abnormal urine sample, epididymal infection, prostatic infection, infections of accessory glands and sexually transmitted diseases. ${ }^{13}$ Karyotyping and genetic counselling is indicated in infertile men with non-obstructive azoospermia and severe oligospermia. ${ }^{11}$ It should also be considered in oligospermic men who are candidate for intracytoplasmic sperm injection (ICSI). ${ }^{19}$

\section{Treatment of Male Infertility}

Identification of the underlying aetiology of infertility is the guide for treatment course. When there is an abnormality in sperm analysis, referral of infertile male to male fertility specialist or reproductive endocrinologist is indicated. If an anatomical abnormality or obstruction is suspected, surgical evaluation and management is required. ${ }^{15}$ 


\section{Pharmacological Treatment}

\section{Hormonal Treatment}

The main functions of testes involve testosterone secretion and spermatogenesis. These functions are regulated by hypothalamic pituitary gonadal axis. High levels of intra-testicular testosterone and FSH stimulation of Sertoli cells are essential for spermatogenesis. The main goal of most of male infertility treatment is to maintain the hypothalamic pituitary axis to increase testicular testosterone. ${ }^{20}$ In secondary hypogonadism (hypogonadotropic hypogonadism) the origin of the disease determines the required treatment for the infertility. Human chorionic gonadotropin (hCG) in combination with Human menopausal gonadotropin ( $\mathrm{hMG}$ ) or purified urinary FSH (urinary-hFSH), or recombinant human FSH ( $r$-hFSH) is the standard treatment of male infertility due to pituitary insufficiency, whereas pulsatile gonadotropin releasing hormone (GnRH) therapy using portable pump is effective in cases of male infertility caused by hypothalamic disorders. Testosterone treatment should be interrupted during $\mathrm{GnRH}$ therapy and resumed after cessation of this therapy. ${ }^{21}$

\section{Drugs}

Dopamine agonists are recommended in cases of hyperprolactinemia mainly due to prolactinoma to reduce tumour size, lower prolactin level, restore gonadal function and reverse infertility. Cabergoline is preferred over other dopamine agonists due to its high effectiveness. In resistant prolactinomas, it is recommended to increase the dose to the maximum tolerated dose before surgical intervention. ${ }^{22}$ Infertile men with low serum testosterone to estradiol ratio can be treated with aromatase inhibitors such as testolactone and anstrazole. The use of such treatments increases testosterone and decreases estradiol levels with a subsequent increase in testosterone to estradiol ratio coupled with an increase in semen parameters. ${ }^{23}$ Sympathomimetic agents are the first line treatment in ejaculatory dysfunction. These agents work by augmenting smooth muscle contraction. They usually used in patients with slowly progressive dysfunction as in diabetic neuropathy. However, they work only for a finite period of time and most of the patients reach to the point at which this treatment is not helpful. ${ }^{24}$ Selective oestrogen receptor modulators
(SERMs) such as clomiphene citrate, tamoxifen, and toremifine are compounds that act on oestrogen receptors as either agonists or antagonists. They share the same mechanism of action. ${ }^{20}$ They inhibit the negative feedback mechanism of oestrogen at the hypothalamus and anterior pituitary levels, increasing the release of $\mathrm{GnRH}$ which increases FSH and LH secretion. Subsequently, there will be an increase in testosterone production and spermatogenesis. ${ }^{25}$ Clomiphene citrate is the drug of choice if there is low testosterone level with normal T/E ratio. ${ }^{26}$ Although no reliable treatment is available to enhance fertility in men with idiopathic infertility, clomiphene citrate showed its ability to increase semen volume, sperm density and total sperm motility in those men. ${ }^{25}$ Antibiotic treatment of genitourinary tract infection resulted in a reduction of seminal leukocytes concentration, amelioration of reactive oxygen species (ROS) generation, and improvement of sperm parameters. ${ }^{27}$ Using of nonsteroidal anti-inflammatory drugs (NSAID) and COX2 inhibitor (rofecoxib) in abacterial leukocytospermia was associated with a reduction in leukocytospermia and recovery of all seminal parameters. ${ }^{28}$ Treatment with NSAID followed by carnitine, in cases of abacterial elevation of seminal leukocytes, is associated with more reduction in ROS and improvement in sperm parameters than the patients treated with these treatments concomitantly. ${ }^{29}$

\section{Supplements (Vitamins and Antioxidants)}

Several antioxidants have been used in a hope to improve sperm quality and fertility. ${ }^{30}$ Different antioxidants at different doses and combinations for various durations have been investigated in numerous previous studies. After three months of treatment of infertile men with vitamin $E$ and selenium there was an improvement in sperm motility with a reduction in sperm MDA level. ${ }^{31}$ Use of antioxidant treatment composed of vitamins $\mathrm{C}, \mathrm{E}$, and $\mathrm{A}$ with micronutrient elements in oligospermic patients with varicocele for 3 months resulted in an improvement of sperm count. ${ }^{32}$ In another study carried out on infertile men with elevated level of DNA-fragmented spermatozoa, administration of vitamins $C$ and $E$ for 2 months efficiently reduced the percentage of DNA-fragmented spermatozoa, ${ }^{33}$ and increased the rate of clinical pregnancy and implantation following ICSI in infertile men with high level of DNA-fragmented spermatozoa. ${ }^{34}$ 
Vitamin E was found to enhance spermatogenesis, reduce germ cell loss, reduce interstitial inflammation and fibrosis, enhance Leydig cells repair and reduce damage caused by high fat diet. ${ }^{35}$ L-carnitine (LC) and L-acetyl-carnitine (LAC) administration for infertile men with idiopathic asthenozoospemia improved sperm function, motility, fertilization capacity, and scavenging capacity in seminal fluid of these patients. ${ }^{36}$ Treatment of idiopathic oligo-asthenoteratospermic infertile men with selenium and $\mathrm{N}$-acetyl-cysteine for 26 weeks resulted in an improvement in all sperm parameters, reduction in serum level of FSH and an elevation of testosterone and inhibin B. ${ }^{37}$ Combination of more than one antioxidant at appropriate doses is a better approach than using a single antioxidant in enhancing the fertilization capacity of infertile men. ${ }^{30}$ It may be prudent to consider using antioxidants in all infertile men who prove to have an oxidative stress. ${ }^{38}$ Further controlled, clinical trials are required to provide a better understanding of the effectiveness and safety of antioxidants and to prepare a precise, valid protocol for their use.

\section{Non-Pharmacological Treatment}

\section{Lifestyle Modification}

Modification of life style, including smoking, obesity, poor nutrition and environmental exposure to toxins should be considered as a first step as all these are related to systemic or seminal increased oxidative stress. ${ }^{39}$ Making a positive life style changes such as weight control and maintenance of a normal weight, reduction of smoking/alcohol, healthy diet rich in fruits and vegetables and use of personal protective equipment that protect from chemical exposure has been encouraged as it would have a beneficial effect on sperm health and reduce the risk of their exposure to oxidative stress. ${ }^{38}$

\section{Surgical Treatment}

Surgical treatment of male infertility involves surgical intervention to correct anatomical abnormality or obstruction as an underlying cause of male infertility. It includes 1) Transurethral resection of ejaculatory ducts which is the classical procedure for the treatment of ejaculatory duct obstruction. It involves resection of the part of prostatic urethra where ejaculatory duct enters. This will un-roof the obstructed duct and allow normal flow of semen. ${ }^{40}$ 2) Vasoepididymostomy for treatment of epididymal obstruction. This microsurgery has been shown to help patients to attain pregnancy spontaneously in $20 \%-40 \%$ without other assisted reproductive techniques. ${ }^{41}$ 3) Vasectomy reversal techniques in men with previous vasectomy. They include vasovasostomy, re -anastomosis of testicular and prostatic ends of the vas, and vasoepididymostomy, connecting the vas to the epididymis. ${ }^{42} 4$ ) For testicular torsion, If the affected testis is viable, orchiopexy with permanent fixation of the testis in the scrotum should be carried out. If the affected testis is grossly necrotic, orchiectomy should be done. Orchiopexy of the contralateral testis is mandatory regardless the viability of the ipsilateral one. ${ }^{43}$ 5) Several surgical techniques have been used for repair of varicocele including microsurgical and laparoscopic varicocelectomy and open surgical ligation of spermatic vein. The most effective and least morbid technique is the microsurgical varicocelectomy. ${ }^{44}$ Early surgical intervention and repair after the trauma is recommended to reduce complications and preserve fertility in testicular trauma cases. ${ }^{45}$

\section{Sperm Retrieval and Assisted Reproductive Technology}

Sperm retrieval is the final common path for men with obstructive azoospermia in whom the anatomic correction cannot be done or failed, or they personally refuse the reconstruction. Men with nonobstructive azoospermia can also be treated effectively with sperm retrieval and assisted reproductive technology (ART). ${ }^{46}$ The purposes of sperm retrieval are to get the adequate numbers of sperm with the best quality for direct use and for cryopreservation, and to reduce reproductive tract damage. Sperm retrieval can be performed through different techniques including; sperm retrieval at the time of surgical reconstruction, microsurgical epididymal sperm aspiration, intraoperative testicular sperm retrieval and percutaneous techniques of epididymal and testicular sperm retrieval. ${ }^{47}$ Assisted reproductive technology encompasses clinical and laboratory procedures in which male and female gametes are manipulated for the purpose of reproduction. It includes in vitro fertilization (IVF), intracytoplasmic sperm injection (ICSI), preimplantation genetic diagnosis, embryo cryopreservation and gestational 
surrogacy. ${ }^{48}$ ICSI is the treatment of choice for most of refractory causes of male infertility including immunologic infertility, azoospermia and severe oligozoospermia, ${ }^{49}$ severe asthenozoospermia, poor sperm morphology, use of surgically retrieved spermatozoa, and failed fertilization in a previous IVF cycle. ${ }^{50}$

\section{CONCLUSION}

Different diagnostic tools and therapeutic options for male infertility are available nowadays which can help infertile men to father children. Identification of the underlying aetiology of infertility is the guide for treatment course. Treatment could be medical or surgical. Sperm retrieval and assisted reproductive technology is the final common path for infertile men who have obstructive azoospermia. It is also an effective treatment for men with non-obstructive azoospermia. Modification of life style has been encouraged as it would have a beneficial effect on male fertility. It is highly important for the researches to be continued to identify the underlying pathology of idiopathic infertility which would help several families to get children.

\section{CONFLICTS OF INTEREST}

The authors declare no conflict of interest.

\section{ACKNOWLEDGEMENT}

This study was funded by International Islamic University Malaysia (IIUM) Research Acculturation Grant Scheme (IRAGS) from IIUM Research Management centre (grant number: IRAGS18-0430044)

\section{REFERENCES}

1. Yilmaz MI, Kocar IH, Baykal Y, Kilic M, Sonmez A, Bulucu F, et al. Effects of statins on oxidative stress. Biol Trace Elem Res. 2004;98 (2):119-27.

2. Kitchen $\mathrm{H}$, Aldhouse $\mathrm{N}$, Trigg A, Palencia R, Mitchell S. A review of patient-reported outcome measures to assess female infertilityrelated quality of life. Health Qual Life Outcomes. 2017;15(86):1-12.
3. Esteves SC, Miyaoka R, Agarwal A. An update on the clinical assessment of the infertile male. Clinics. 2011;66(4):691-700.

4. Fehintola A, Funmito F, Ogunlaja OA, Awotunde OT, IP O, U O. Social Meaning and Consequences of Infertility in Ogbomoso, Nigeria. Sudan J Med Sci. 2017;12(2):63-77.

5. Olooto W. Infertility in malea; risk factors, causes and management- A review. J Microbiol Biotechnol Res. 2012;2(4):641-5.

6. Agarwal A, Mulgund A, Hamada A, Chyatte MR. $A$ unique view on male infertility around the globe. Reprod Biol Endocrinol. 2015;13(37):1-9.

7. Carlsen E, Giwercman A, Keiding N, Skakkebaek $N E$. Evidence for decreasing quality of semen during past 50 years. Bmj. 1992;305:609-13.

8. Eisenberg ML, Li S, Behr B, Cullen MR, Galusha $D$, Lamb DJ, et al. Semen quality, infertility and mortality in the USA. Hum Reprod. 2014;29 (7):1567-74.

9. Chachamovich JLR, Chachamovich E, Ezer H, Cordova FP, Fleck MMP, Knauth DR, et al. Psychological distress as predictor of quality of life in men experiencing infertility: a crosssectional survey. Reprod Health. 2010;7(3):1-9.

10. Sharlip ID, Jarow JP, Belker AM, Lipshultz LI, Sigman M, Thomas AJ, et al. Best practice policies for male infertility. Fertil Steril. 2002;77(5):873-82.

11. Jarow J, Sigman M, Kolettis PN, Lipshultz LR, Mcclure RD, Nangia AK, et al. The Optimal Evaluation of the Infertile Malea: AUA Best Practice Statement. American Urological Association Education and Research, Inc. 2010. p. 1-38.

12. Pfeifer $S$, Butts $S$, Dumesic D, Fossum G, Gracia C, La Barbera A, et al. Diagnostic evaluation of the infertile male: A committee opinion. Fertil Steril. 2015;103(3):e18-25.

13. Jungwirth A, Giwercman A, Tournaye $H$, Diemer T, Kopa Z, Dohle G, et al. European association of urology guidelines on male infertility: The 2012 update. Eur Urol. 2012;62 (2):324-32.

14. WHO. WHO laboratory manual for the Examination and processing of human semen. 5th Ed. Geneva: WHO Press. 2010. 1-286 p.

15. Lindsay TJ, Vitrikas KR. Evaluation and treatment of infertility. Am Fam Physician. 2015;91(5):308-14.

16. Kolettis PN. Evaluation of the subfertile man. Am Fam Physician. 2003;67(10):2165-73. 
17. Pavlovich CP, King P, Goldstein M, Schlegel PN. Evidence of a treatable endocrinopathy in infertile men. J Urol. 2001;165(3):837-41.

18. Krassas GE, Poppe K, Glinoer D. Thyroid Function and Human Reproductive Health. Endocr Rev. 2010;31(5):702-55.

19. Foresta C, Garolla A, Bartoloni L, Bettella A, Ferlin A. Genetic abnormalities among severely oligospermic men who are candidates for intracytoplasmic sperm injection. J Clin Endocrinol Metab. 2005;90(1):152-6.

20. Dabaja AA, Schlegel PN. Medical treatment of male infertility. Transl Androl Urol. 2014;3(1):9 $-16$.

21. Zitzmann M, Nieschlag E. Hormone substitution in male hypogonadism. Mol Cell Endocrinol. 2000;161(2):73-88.

22. Melmed S, Casanueva FF, Hoffman AR, Kleinberg DL, Montori VM, Schlechte JA, et al. Diagnosis and treatment of hyperprolactinemia: An endocrine society clinical practice guideline. J Clin Endocrinol Metab. 2011;96(2):273-88.

23. Raman JD, Schlegel PN. Aromatase inhibitors for male infertility. J Urol. 2002;167(2 I):6249.

24. Ohl DA, Quallich SA, Sønksen J, Brackett NL, Lynne CM. Anejaculation and Retrograde Ejaculation. Urol Clinincs North Am. 2008;35:211-20.

25. Zaman S, Zulfiqar S, Khan MSK. Evaluation of Effects of Clomiphene Citrate on Serum Testosterone \& FSH Levels and Seminal Parameters in Idiopathic Oligospermia. Biomedica. 2009;25:48-51.

26. Ring J, Lwin A, Köhler T. Current medical management of endocrine-related male infertility. Asian J Androl. 2016;18(3):357-63.

27. Vicari E. Effectiveness and limits of antimicrobial treatment on seminal leukocyte concentration and related reactive oxygen species production in patients with male accessory gland infection. Hum Reprod. 2000;15(12):2536-44.

28. Gambera L, Serafini F, Morgante G, Focarelli R, Leo D, Piomboni P. Sperm quality and pregnancy rate after COX-2 inhibitor therapy of infertile males with abacterial leukocytospermia. Hum Reprod. 2007;22:1-5.

29. Vicari E, Vignera S La, Calogero AE. Antioxidant treatment with carnitines is effective in infertile patients with prostatovesiculoepididymitis and elevated seminal leukocyte concentrations after treatment with nonsteroidal antiinflammatory compounds. Fertil Steril. 2002;78(6):1203-8.

30. Lanzafame FM, Vignera S La, Vicari E, Calogero $\mathrm{AE}$. Oxidative stress and medical antioxidant treatment in male infertility. Reprod Biomed Online. 2009;19(5):638-59.

31. Keskes-Ammar L, Feki-Chakroun N, Rebai T, Sahnoun Z, Ghozzi H, Hammami S, et al. Sperm Oxidative Stress and the Effect of an Oral Vitamin E and Selenium Supplement on Semen Quality in Infertile Men. Arch Androl. 2003;49(2):83-94.

32. Galatioto GP, Gravina GL, Angelozzi G, Sacchetti A, Innominato PF, Ranieri GP. G, et al. May antioxidant therapy improve sperm parameters of men with persistent oligospermia after retrograde embolization for varicocele? World J Urol. 2008;26:97-102.

33. Greco E, lacobelli M, Rienzi L, Ubaldi F, Ferrero S, Tesarik J. Reduction of the incidence of sperm DNA fragmentation by oral antioxidant treatment. J Androl. 2005;26 (3):349-53.

34. Greco E, Romano S, lacobelli M, Ferrero S, Baroni E, Minasi MG, et al. ICSI in Cases of Sperm DNA Damage : Beneficial Effect of Oral Antioxidant Treatment. Hum Reprod. 2005;20:2590-4.

35. Al-Kushi A, El Sawy NA, M M H. Therapeutic Effect of Vitamin $\mathrm{E}$ on Testicular Tissue Damage Caused by Obesity. J Obes Weight Loss Ther. 2016;06(05):1-5.

36. Balercia G, Regoli F, Armeni T, Koverech A, Mantero F, Boscaro M. Placebo-controlled double-blind randomized trial on the use of $L$ carnitine , $\mathrm{L}$-acetylcarnitine , or combined $\mathrm{L}$ carnitine and $\mathrm{L}$-acetylcarnitine in men with idiopathic asthenozoospermia. Fertil Steril. 2005;84(3):662-71.

37. Safarinejad MR, Safarinejad S. Efficacy of Selenium and / or N-Acetyl-Cysteine for Improving Semen Parameters in Infertile Menם: A Double-Blind, Placebo Controlled, Randomized Study. J Urol. 2009;181(2):741-51.

38. Tremellen K. Oxidative stress and male infertility - a clinical perspective. Hum Reprod Updat. 2008;14(3):243-58.

39. Kefer JC, Agarwal A, Sabanegh E. Role of antioxidants in the treatment of male 
infertility. Int J Urol. 2009;16:449-57.

40. Onur MR, Orhan Ý, Fýrdolap F, Onur R,

Kocakoç E. Clinical and Radiological Evaluation of Ejaculatory Duct Obstruction. J Reprod Syst. 2007 Jan 9;53(4):179-86.

41. American Society for Reproductive Medicine. Report on management of obstructive azoospermia. Fertil Steril. 2004 Sep;82(SUPPL. 1):137-41

42. Rayala BZ, Viera AJ. Common Questions About Vasectomy. Am Fam Physician. 2013;88 (11):757-61.

43. Sharp VJ, Kieran K, Arlen AM. Testicular torsion: Diagnosis, evaluation, and management. Am Fam Physician. 2013;88 (12):835-40.

44. Ding $\mathrm{H}$, Tian J, Du W, Zhang L, Wang $\mathrm{H}$, Wang Z. Open non-microsurgical, laparoscopic or open microsurgical varicocelectomy for male infertility: A meta-analysis of randomized controlled trials. BJU Int. 2012;110(10):153642.

45. Kukadia AN, Ercole CJ, Gleich P, Hensleigh $\mathrm{H}$, Pryor JL. Testicular trauma: Potential impact on reproductive function. J Urol. 1996;156 (5):1643-6.

46. Velasquez $M$, Tanrikut $C$. Surgical management of male infertility: an update. Transl Androl Urol. 2014;3(1):64-76.

47. ASRM Practice Committee. Sperm retrieval for obstructive azoospermia. Fertil Steril. 2008;90 (SUPP 3L.):S213-218.

48. Sabarre K, Khan Z, Whitten AN, Remes O, Phillips KP. A qualitative study of Ottawa university students ' awareness, knowledge and perceptions of infertility, infertility risk factors and assisted reproductive technologies (ART). Reprod Health. 2013;10(41):1-10.

49. Esteves SC, Schneider DT. Male Infertility and Assisted Reproductive Technology: Lessons from the IVF. Open Reprod Sci J. 2011;3(1):138 -53 .

50. Khorram O, Patrizio P, Wang C, Swerdloff R. Reproductive technologies for male infertility. The Journal of Clinical Endocrinology \& Metabolism. 2001;86(6):2373-9. 